\title{
Bevacizumab is Effective for Recurrent Papillary Tumor of the Pineal Region: First Report
}

\author{
Adam L. Cohen $^{\mathrm{a}}$ Karen Salzman $^{\mathrm{b}}$ Cheryl Palmer $^{\mathrm{c}}$ Randy Jensen ${ }^{\mathrm{d}}$ \\ Howard Colman ${ }^{\text {a, }}$ \\ ${ }^{a}$ Huntsman Cancer Institute, and Departments of ${ }^{\mathrm{b}}$ Radiology, ${ }^{\mathrm{C}}$ Pathology and \\ ${ }^{\mathrm{d}}$ Neurosurgery, University of Utah, Salt Lake City, Utah, USA
}

\section{Key Words}

Pineal tumor · Bevacizumab · Angiogenesis

\begin{abstract}
Papillary tumor of the pineal region (PTPR) is a rare brain tumor that probably arises from ependymal cells. There are no known systemic treatments for PTPR once it is refractory to surgery and radiation. We present the first case of a durable radiographic and clinical response of a PTPR to bevacizumab, an antibody against vascular endothelial growth factor, despite multiple prior treatments. Bevacizumab may be an effective treatment for PTPR.
\end{abstract}

\section{Introduction}

Papillary tumor of the pineal region (PTPR) is a rare tumor with no known effective systemic therapy. We report here the first case of demonstrable radiologic response to a systemic therapy, bevacizumab, in multiple recurrent PTPR.

\section{Case Report}

A 31-year-old right-handed man was referred for treatment of recurrent PTPR in the posterior fossa with symptoms including headache, inability to open his eyes, confusion, and obstructive hydrocephalus. He originally presented at 24 years of age with obstructive hydrocephalus and a $1.5-\mathrm{cm}$ enhancing pineal mass. Following placement of a ventriculo- 
Cohen et al.: Bevacizumab is Effective for Recurrent Papillary Tumor of the Pineal Region: First Report

peritoneal shunt and a nondiagnostic biopsy, he underwent craniotomy and resection. The pathology report showed a papillary neoplasm negative for GFAP, synaptophysin, PLAF, and MEC, and positive for CAM 5.2 and cytokeratin 3. The MIB-1 index was 15\%. The pathology was reviewed at Johns Hopkins University and has subsequently been reviewed by us; the diagnosis has been confirmed to be PTPR (fig. 1). Because of residual tumor, he received 5,940 cGy of radiotherapy in 33 fractions.

Seven months later, he developed a new 1 -cm enhancing mass in the left lateral ventricle that increased in size over 3 months. New lesions also developed in the posterior fossa, and he was treated with Gamma Knife to 5 locations. Eighteen months later, he had Gamma Knife to 4 additional posterior fossa lesions, resulting in shrinkage of the lesions on MRI and decreased steroid requirement. Over the next 2 years, he had waxing and waning enhancement over the right inferior temporal lobe that was treated as radiation necrosis with pentoxifylline and vitamins, with subsequent resolution of the enhancement.

By the age of 28, he had increased edema and mass effect in the left cerebellum and underwent a posterior fossa craniotomy. The specimen was about $70 \%$ necrosis and gliosis and $30 \%$ viable PTPR. Because of residual enhancement, dose-dense temozolomide (75 $\mathrm{mg} / \mathrm{m}^{2}$ for 21 days of a 28-day cycle) was given for 11 cycles. He then developed increased enhancement and worsening balance while on the temozolomide and was treated with 2 cycles of PCV and 2 cycles of carboplatin and etoposide.

His MRI then showed stable 1-cm lesions in the occipital lobe but an enlarging $4.6 \times 3.2$ $\times 2.8-\mathrm{cm}$ mass in the midline posterior cerebellum and a $1.7 \times 1 \times 2.8-\mathrm{cm}$ mass abutting the fourth ventricle, both with surrounding edema and mass effect, and he was referred to the University of Utah (fig. 2). An extraventricular drain was placed, followed by a ventriculoperitoneal shunt. Reirradiation was recommended, but the patient declined due to prior toxicity.

Twelve days later, at the age of 31 , he began bevacizumab $10 \mathrm{mg} / \mathrm{kg}$ every 2 weeks. The enhancing midline cerebellar mass decreased in size to $2 \times 1.4 \times 2.8 \mathrm{~cm}(80 \%$ decrease in the cross-sectional area) and the periventricular mass decreased to $1.7 \times 0.8 \times 0.9 \mathrm{~cm}$ in 1 month (20\% decrease in the cross-sectional area), and both remained stable for 13 months. The FLAIR signal remained decreased as well (fig. 3). His dexamethasone dose remained at $2 \mathrm{mg}$ daily for 6 months and then was tapered off.

After 13 months, both masses increased in size to $3.1 \times 1.9 \mathrm{~cm} \mathrm{(120 \% )} \mathrm{and} 2.2 \times 1.1 \mathrm{~cm}$ $(84 \%)$ in cross-sectional area, respectively (fig. 4). Oral etoposide $50 \mathrm{mg} / \mathrm{m}^{2}$ for 21 out of 28 days was added, and his mass remained stable on MRI at 2, 5 (fig. 5: white arrow indicates tumor; black arrow indicates shunt), and 7 months. After 7 months of bevacizumab and etoposide, he had increased dysarthria and ataxia, and MRI demonstrated growth of the masses by $220 \%$ in cross-sectional area to $5.6 \times 3.5 \mathrm{~cm}$ and by $100 \%$ to $3.1 \times 1.7 \mathrm{~cm}$. He again declined radiation and has continued on bevacizumab and etoposide. His dexamethasone dose has varied between 1 and $2 \mathrm{mg}$ per day.

\section{Discussion}

PTPR is a rare tumor originally described in 2003 [1] and accepted into the WHO classification of central nervous system tumors in 2007 [2]. Fewer than 100 cases have been reported, with most focusing on the histologic or radiologic appearance. The cell of origin of PTPR is unknown. Based on the location and immunohistochemical staining pattern, it has been proposed to be of ependymal cell origin from the circumventricular organs $[3,4]$. Therefore, treatments effective for gliomas may be effective for PTPR. However, data on 


\begin{tabular}{l|l}
\hline DOI: $10.1159 / 000354753$ & $\begin{array}{l}\text { C } 2013 \text { S. Karger AG, Basel } \\
\text { www.karger.com/cro }\end{array}$ \\
\hline
\end{tabular}

Cohen et al.: Bevacizumab is Effective for Recurrent Papillary Tumor of the Pineal Region: First Report

successful systemic therapy for PTPR are lacking, and optimal therapy for recurrent PTPR is not well characterized. In our case, prolonged stabilization was seen with both etoposide and bevacizumab. Bevacizumab also greatly improved his quality of life.

PTPR has been described as very vascular [5], but microvascular proliferation has not been noted. However, most pathologic descriptions of PTPR are from primary or early resections, rather than from recurrences. In 1 case, a resected recurrent PTPR had an increased proliferation rate, increased anaplasia, and necrosis without microvascular proliferation [6].

In published series, the primary treatment for PTPR has been surgery and/or radiation/radiosurgery [7-19]. Neither radiation nor chemotherapy has been shown to improve survival [20]. Other treatments for PTPR have included adjuvant and neoadjuvant temozolomide after complete resection, adjuvant temozolomide/etoposide after complete resection, adjuvant carboplatin/etoposide following resection, and ACNU given after radiation but before surgery $[6,7,21,22]$. When the treatment was either adjuvant after surgery and/or radiation or concomitant with radiation, the independent effect of the systemic chemotherapy could not be assessed. In another single patient report, a woman with recurrent PTPR had a partial response to temozolomide that was started due to lack of change in the tumor 2 months after radiation [21]. Due to the timing, the independent effects of radiation and temozolomide in that case cannot be known for certain, but it suggests a sensitivity to temozolomide. In another case, the treatment effect was not noted after neoadjuvant treatment with temozolomide [6].

Bevacizumab is an antiangiogenic antibody against vascular endothelial growth factor. Responses have been reported in ependymoma [23], which is of interest relative to the case reported here due to the potential, commonly hypothesized origin of ependymoma and PTPR from cells in the ependymal region. Here, we describe a successful long-term response to bevacizumab in a multiple recurrent and chemotherapy-resistant PTPR. Thus, bevacizumab may be an active agent in this rare tumor and should be considered for cases of recurrent PTPR that are not operable or amenable/responsive to radiation or standard cytotoxic treatments.

\section{References}

1 Jouvet, A, Fauchon F, Liberski P, Saint-Pierre G, Didier-Bazes M, Heitzmann A, Delisle MB, Biassette HA, Vincent S, Mikol J, Streichenberger N, Ahboucha S, Brisson C, Belin MF, Fevre-Montange M: Papillary tumor of the pineal region. Am J Surg Pathol 2003;27:505-512.

-2 Louis DN, Ohgaki H, Wiestler OD, Cavenee WK, Burger PC, Jouvet A, Scheithauer BW, Kleihues P: The 2007 WHO classification of tumours of the central nervous system. Acta Neuropathol 2007;114:97-109.

-3 Fevre Montange M, Vasiljevic A, Bergemer Fouquet AM, Bernier M, Champier J, Chretien F, Figarella-Branger D, Kemeny JL, Lechapt-Zalcman E, Michalak S, Miquel C, Mokthari K, Pommepuy I, Quintin Roue I, Rousseau A, Saint-Pierre G, Salon C, Uro-Coste E, Varlet P, Kratzer I, Ghersi-Egea JF, Jouvet A: Histopathologic and ultrastructural features and claudin expression in papillary tumors of the pineal region: a multicenter analysis. Am J Surg Pathol 2012;36:916-928.

-4 Szathmari A, Champier J, Ghersi-Egea JF, Jouvet A, Watrin C, Wierinckx A, Fevre Montange M: Molecular characterization of circumventricular organs and third ventricle ependyma in the rat: potential markers for periventricular tumors. Neuropathology 2013;33:17-29.

5 Li J, Recinos PF, Orr BA, Burger PC, Jallo GI, Recinos VR: Papillary tumor of the pineal region in a 15-monthold boy. J Neurosurg Pediatr 2011;7:534-538.

6 Lechapt-Zalcman E, Chapon F, Guillamo JS, Khouri S, Menegalli-Boggelli D, Loussouarn D, Fevre-Montange $\mathrm{M}$, Jouvet A: Long-term clinicopathological observations on a papillary tumour of the pineal region. Neuropathol Appl Neurobiol 2011;37:431-435.

7 Rickard KA, Parker JR, Vitaz TW, Plaga AR, Wagner S, Parker JC Jr: Papillary tumor of the pineal region: two case studies and a review of the literature. Ann Clin Lab Sci 2011;41:174-181. 


\section{Case Reports in Oncology}

\begin{tabular}{l|l}
\hline Case Rep Oncol 2013;6:434-440 \\
\hline DOI: $10.1159 / 000354753$ & $\begin{array}{l}\text { C 2013 S. Karger AG, Basel } \\
\text { www.karger.com/cro }\end{array}$ \\
\hline
\end{tabular}

Cohen et al:: Bevacizumab is Effective for Recurrent Papillary Tumor of the Pineal Region: First Report

8 Patel SK, Tomei KL, Christiano LD, Baisre A, Liu JK: Complete regression of papillary tumor of the pineal region after radiation therapy: case report and review of the literature. J Neurooncol 2012;107:427-434.

-9 Epari S, Bashyal R, Malick S, Gupta T, Moyadi A, Kane SV, Bal M, Jalali R: Papillary tumor of pineal region: report of three cases and review of literature. Neurol India 2011;59:455-460.

10 Poulgrain K, Gurgo R, Winter C, Ong B, Lau Q: Papillary tumour of the pineal region. J Clin Neurosci 2011;18:1007-1017.

11 Cardenas R, Javalkar V, Haydel J, Wadhwa R, Fowler M, Scheithauer B, Nanda A: Papillary tumor of pineal region: prolonged control rate after gamma knife radiosurgery - a case report and review of literature. Neurol India 2010;58:471-476.

12 Cerase A, Vallone IM, Di Pietro G, Oliveri G, Miracco C, Venturi C: Neuroradiological follow-up of the growth of papillary tumor of the pineal region: a case report. J Neurooncol 2009;95:433-435.

$\checkmark 13$ Boco T, Aalaei S, Musacchio M, Byrne R, Cochran E: Papillary tumor of the pineal region. Neuropathology 2008;28:87-92.

14 Kawahara I, Tokunaga Y, Yagi N, Iseki M, Abe K, Hayashi T: Papillary tumor of the pineal region. Neurol Med Chir (Tokyo) 2007;47:568-571.

15 Buffenoir K, Rigoard P, Wager M, Ferrand S, Coulon A, Blanc JL, Bataille B, Listrat A: Papillary tumor of the pineal region in a child: case report and review of the literature. Childs Nerv Syst 2008;24:379-384.

-16 Santarius T, Joseph JA, Tsang KT, O’Donovan DG, Kirollos RW: Papillary tumour of the pineal region. Br J Neurosurg 2008;22:116-120.

17 Dagnew E, Langford LA, Lang FF, DeMonte F: Papillary tumors of the pineal region: case report. Neurosurgery 2007;60:E953-E955, discussion E953-E955.

18 Kern M, Robbins P, Lee G, Watson P: Papillary tumor of the pineal region - a new pathological entity. Clin Neuropathol 2006;25:185-192.

19 Fevre-Montange M, Hasselblatt M, Figarella-Branger D, Chauveinc L, Champier J, Saint-Pierre G, Taillandier L, Coulon A, Paulus W, Fauchon F, Jouvet A: Prognosis and histopathologic features in papillary tumors of the pineal region: a retrospective multicenter study of 31 cases. J Neuropathol Exp Neurol 2006;65:10041011.

20 Fauchon F, Hasselblatt M, Jouvet A, Champier J, Popovic M, Kirollos R, Santarius T, Amemiya S, Kumabe T, Frappaz D, Lonjon M, Fevre Montange M, Vasiljevic A: Role of surgery, radiotherapy and chemotherapy in papillary tumors of the pineal region: a multicenter study. J Neurooncol 2013;112:223-231.

-21 Lorenzetti M, Motta F, Campanella R, Bauer D, Assi A, Arienta C, Gaini SM, Caroli M: Adjuvant temozolomide chemotherapy for treatment of papillary tumor of the pineal region. World Neurosurg 2011;76:160-163.

-22 Nakamura H, Makino K, Kochi M, Nakazato Y, Kuratsu J: Successful treatment of neoadjuvant therapy for papillary tumor of the pineal region. Brain Tumor Pathol 2009;26:73-77.

23 Green RM, Cloughesy TF, Stupp R, DeAngelis LM, Woyshner EA, Ney DE, Lassman AB: Bevacizumab for recurrent ependymoma. Neurology 2009;73:1677-1680.

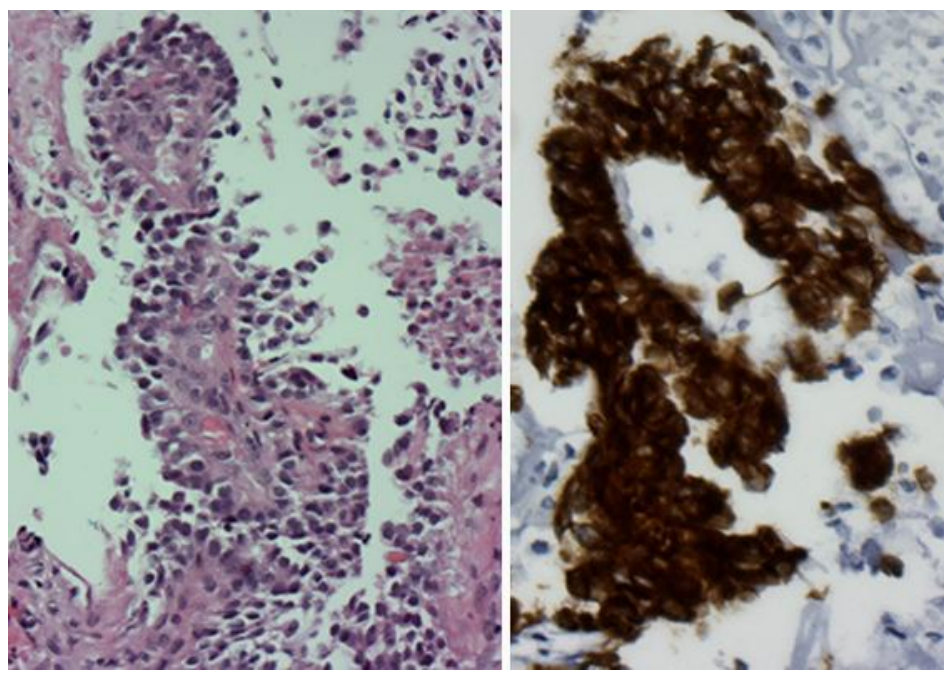

Fig. 1. HE-stained sections of the tumor demonstrate an epithelial tumor with papillary features (left; HE $\times 400$ ). The tumor is strongly positive for keratin immunostaining (right; Cam5.2 ×600). 


\section{Case Reports in Oncology}

\begin{tabular}{l|l}
\hline Case Rep Oncol 2013;6:434-440 \\
\hline DOI: $10.1159 / 000354753$ & $\begin{array}{l}\text { C 2013 S. Karger AG, Basel } \\
\text { www.karger.com/cro }\end{array}$ \\
\hline
\end{tabular}

Cohen et al.: Bevacizumab is Effective for Recurrent Papillary Tumor of the Pineal Region: First Report
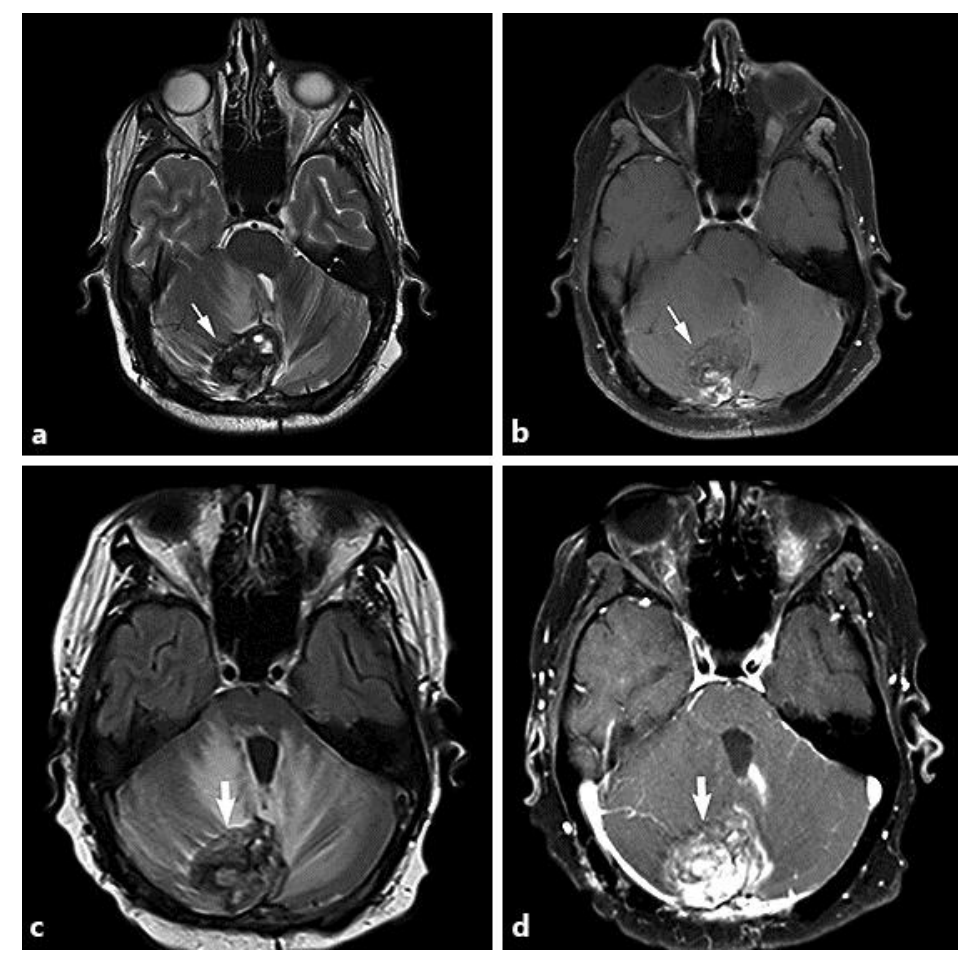

Fig. 2. MRI of the tumor 2 months before (a, b) and then again immediately before (c, d) bevacizumab treatment. a Magnetic resonance (MR) axial T2 image of the posterior fossa shows a large heterogeneous mass (white arrow) in the posterior cerebellum with surrounding hyperintense signal likely related to vasogenic edema and treatment effects. b Post-contrast T1-weighted image with fat saturation shows heterogeneous enhancement of the mass (white arrow) related to the patient's known metastatic disease from his PTPR. c MR axial FLAIR image of the posterior fossa shows an increase in the size of the heterogeneous mass (white arrow) in the posterior cerebellum with surrounding hyperintense signal likely related to vasogenic edema and treatment effects. d Post-contrast T1-weighted image with fat saturation shows an increase in heterogeneous enhancement of the mass (white arrow) related to the patient's known metastatic disease from his PTPR. The mass measured $4.6 \mathrm{~cm}$. A linear focus of enhancement along the left fourth ventricle is related to the patient's metastatic disease. 


\section{Case Reports in Oncology}

\begin{tabular}{l|l}
\hline Case Rep Oncol 2013;6:434-440 \\
\hline DOI: 10.1159/000354753 & $\begin{array}{l}\text { C 2013 S. Karger AG, Basel } \\
\text { www.karger.com/cro }\end{array}$ \\
\hline
\end{tabular}

Cohen et al.: Bevacizumab is Effective for Recurrent Papillary Tumor of the Pineal Region: First Report

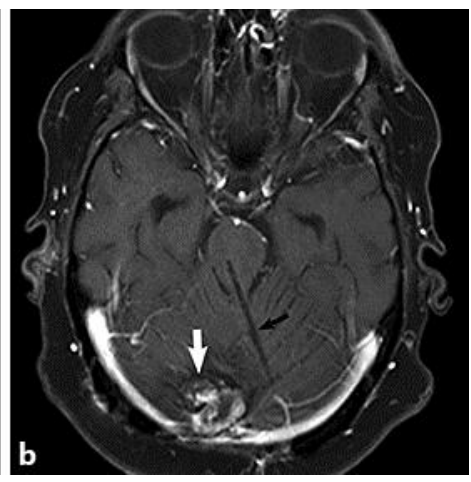

Fig. 3. MRI of the tumor after bevacizumab treatment. a Magnetic resonance axial FLAIR image of the posterior fossa shows a decrease in the size of the heterogeneous mass (white arrow) in the posterior cerebellum with a decrease in the associated edema after bevacizumab. The extraventricular drain is partially visualized (black arrow). b Post-contrast T1-weighted image with fat saturation shows a decrease in the heterogeneously enhancing mass (white arrow) after bevacizumab. The mass measured 2 $\mathrm{cm}$ and was stable for 13 months. The extraventricular drain is partially visualized (black arrow).
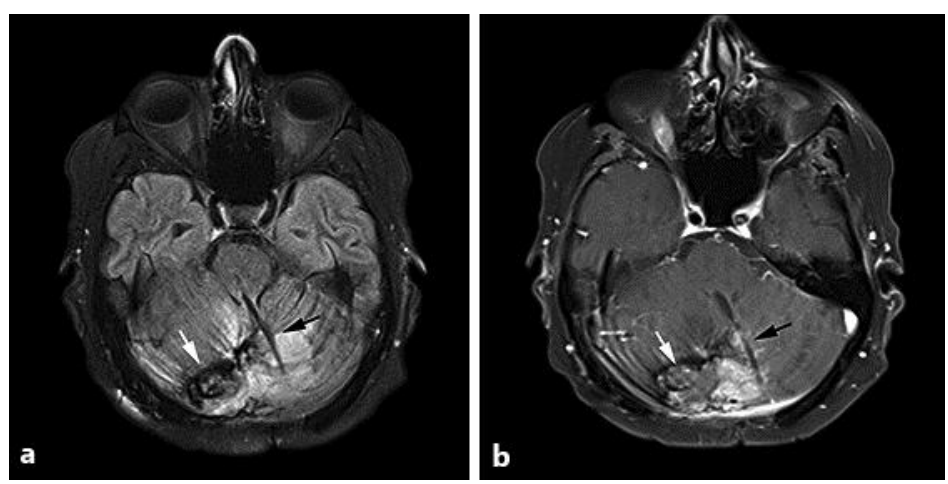

Fig. 4. MRI of the tumor after 13 months of bevacizumab treatment. a Magnetic resonance axial FLAIR image of the posterior fossa shows an increase in the size of the heterogeneous mass (white arrow) in the posterior cerebellum with an increase in the associated edema. The extraventricular drain is partially visualized (black arrow). b Post-contrast T1-weighted image with fat saturation shows an increase in the heterogeneously enhancing mass (white arrow) after bevacizumab. The extraventricular drain is partially visualized (black arrow). 


\section{Case Reports in Oncology}
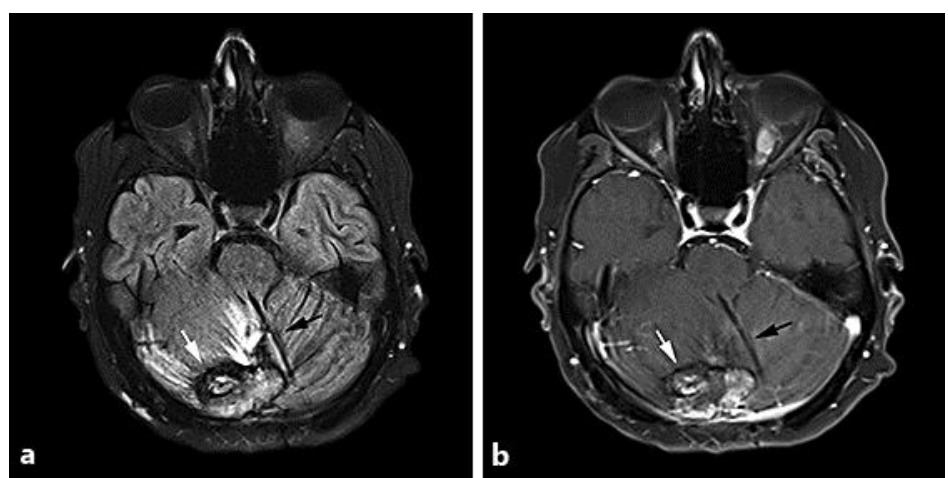

Fig. 5. MRI of the tumor after 5 months of bevacizumab and etoposide treatment. a Magnetic resonance axial FLAIR image of the posterior fossa shows stability in the size of the heterogeneous mass (white arrow) in the posterior cerebellum. The extraventricular drain is partially visualized (black arrow). b Post-contrast T1-weighted image with fat saturation shows stability in the heterogeneously enhancing mass (white arrow). The extraventricular drain is partially visualized (black arrow). 